\title{
Urology as rehabilitation medicine: a literature review
}

\author{
Tae Beom Kim, Chang Hee Kim, Kwang Taek Kim, Sang Jin Yoon, Kyung Jin Chung* \\ Department of Urology, Gachon University Medical Center, Gachon University School of Medicine, Incheon, Korea
}

As a urologist, we usually encounter with two representative functional behaviors, namely, voiding and sexual function. These are not only important but also complex and synchronized so if these functions are impaired, patients need active functional rehabilitation to recover. These functional impairments should be recognized and corrected early because they could not only cause direct damage to the affected functions but also have harmful consecutive consequences such as kidney damage due to voiding abnormality and self-esteem damage due to decreased sexual function. Numerous rehabilitative methods are currently available, which help minimize the negative effects of these functional impairments. In terms of voiding function, pelvic floor muscle exercise, biofeedback, functional magnetic stimulation, neuromodulation, and clean intermittent self-catheterization are representative rehabilita- tion modalities. In case of children, extra-attention should be paid because this might affect their entire life. In impairment of sexual function, early intervention to maintain male erection is the main target of rehabilitation to prevent corporal fibrosis and penile deformity and increase recovery chance in patients who underwent radical prostatectomy or major surgery. In this review, we will elucidate various rehabilitation methods in urology to further increase our understanding of the rehabilitative characteristics of urology and widen our view of rehabilitation medicine.

Keywords: Rehabilitation medicine, Urology, Bladder, Erectile dysfunction

mately affects the quality of life (QoL) (Choi and Bae, 2016). Therefore, it is very important to normalize or, at least, minimize the negative effects of voiding abnormality to the patients who have distorted voiding mechanism.

Voiding abnormality in children has additional importance because of their young age. Children should establish the basics of a healthy urination mechanism and abnormal voiding behavior happens repeatedly during their whole life (Costantini et al., 2018). Therefore, when we treat pediatric patients with voiding abnormality, more attention should be paid in addition to consideration of the general abnormal voiding aspects. Furthermore, children are very vulnerable, in that abnormal voiding might affect not only their personality but also their psychosocial aspect (Costantini et al., 2018).

Sexual function is a complex behavior that is influenced by psychological and physical factors, and it affects not only the QoL of individuals but also their interpersonal relationship of couple or family (Eton and Lepore, 2002). In sexual function, it has both
${ }^{*}$ Corresponding author: Kyung Jin Chung (iD https://orcid.org/0000-0003-0153-7814 Department of Urology, Gachon University Gil Medical Center, Gachon University School of Medicine, 21 Namdong-daero 774beon-gil, Namdong-gu, Incheon 21565, Korea

Tel: +82-32-460-3334, Fax: +82-32-460-8414, E-mail: Kjchung@gilhospital.com Received: April 16, 2018 / Accepted: May 14, 2018
This is an Open Access article distributed under the terms of the Creative Commons Attribution Non-Commercial License (http://creativecommons.org/licenses/by-nc/4.0/) which permits unrestricted non-commercial use, distribution, and reproduction in any medium, provided the original work is properly cited. 
masculine and feminine aspects, but given the paucity of studies on and poor knowledge about female sexuality, sexual rehabilitation usually refers to male sexual dysfunction, also known as erectile dysfunction (ED). In particular, the concept of sexual rehabilitation is usually applicable in cases of ED cause by nerve injury after spinal trauma and major surgery, such as radical prostatectomy (RP) (Eton and Lepore, 2002; Walsh and Schlegel, 1988). Penile rehabilitation was devised from the theory that early penile circulation might help recovery and prevent corporeal fibrosis and penile contracture (Briganti and Montorsi, 2006).

At present, many urologic approaches have been developed and performed to restore or preserve voiding and sexual functions. In this review, we will introduce the rehabilitative aspect of urology and review various rehabilitation methods. We expect that may contribute to the expanding view of rehabilitation experts and may have any type of chance to cooperate between rehabilitation and urology field.

\section{BLADDER REHABILITATION}

The urinary bladder is the major organ of urology; hence, various bladder rehabilitation methods for diverse functional abnormal status affecting the bladder are being performed. Not only the major disease state such as stress urinary incontinence (SUI), overactive bladder $(\mathrm{OAB})$, neurogenic bladder $(\mathrm{NB})$, but also the abnormal voiding status after RP, and orthotopic neobladder (ONB) after radical cystectomy are representative status of the bladder that needs rehabilitation. For these disease states, pelvic floor muscle exercise (PFE), bladder training, functional magnetic stimulation (FMS), electrical neuromodulation, and clean intermittent self-catheterization (CIC) can be employed as rehabilitation methods (Olujide and O'Sullivan, 2005) (Fig. 1).

PFE, first described by Kegel, is the exercise that was thought to strengthen the pelvic floor muscle to further support the urethra (Dumoulin et al., 2014). In this technique, patients are trained to consciously contract their pelvic floor muscles to prevent SUI, and, when there is increasing abdominal pressure or pelvic muscle spasm, it helps relaxation of such muscles particularly in OAB or urge incontinence (Dumoulin et al., 2014). Moreover, concomitant biofeedback could synergistically reinforce the PFE (Newman, 2014).

Bladder retraining might be helpful to treat $\mathrm{OAB}$ with or without urge incontinence by gradual and continuous elongation of urination interval in timed voiding (Wein, 2005). FMS has been adopted as a form of physical therapy for OAB (But, 2003). Since the Food and Drug Administration approved magnetic

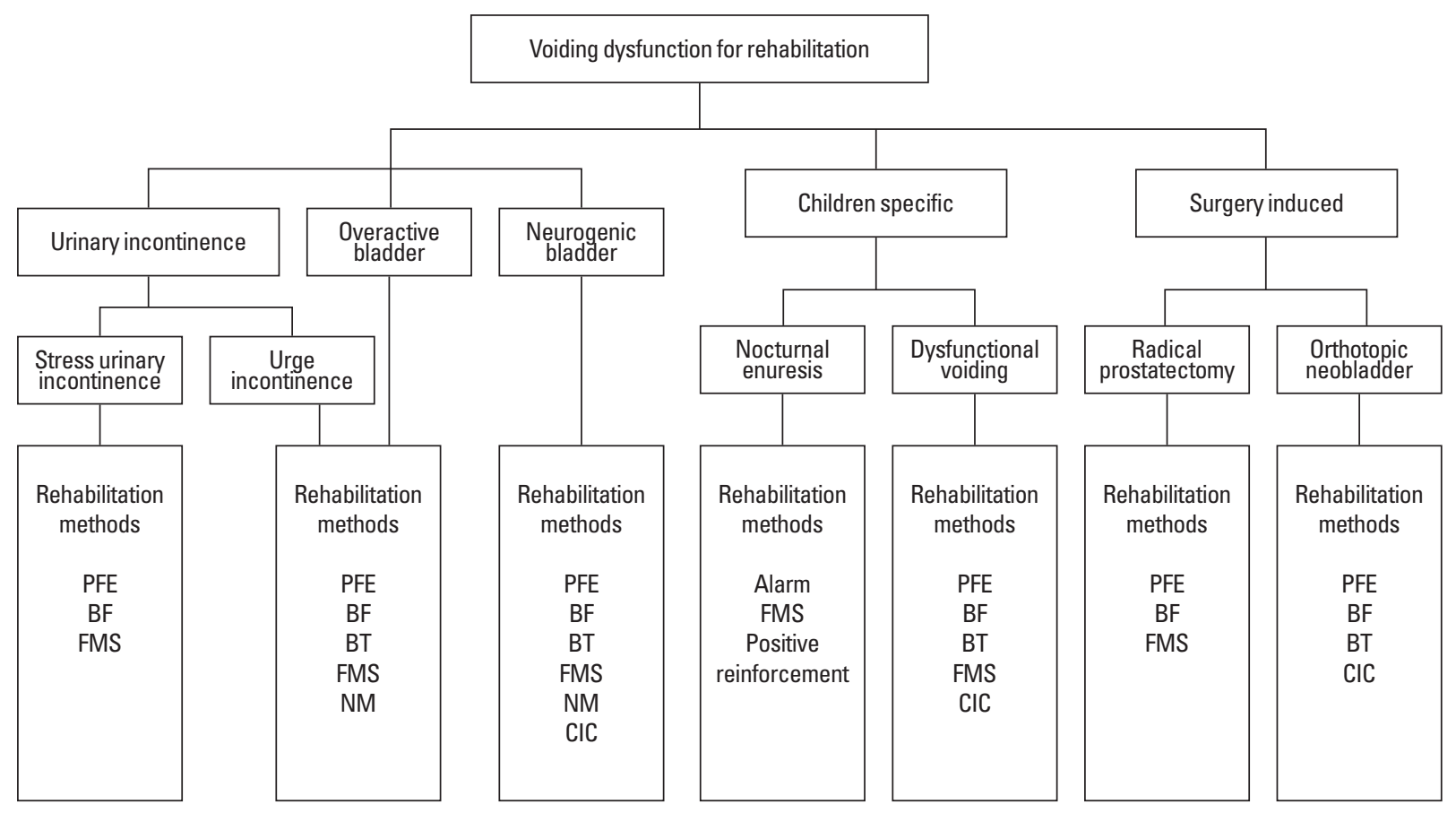

Fig. 1. Voiding dysfunction and its rehabilitation modality: schematic view. PFE, pelvic floor exercise; BF, bio-feedback; FMS, functional magnetic stimulation; BT, bladder training; NM, neuromodulation; $\mathrm{ClC}$, clean intermittent catheterization. 
stimulation for urinary incontinence in 1998, electrical muscle stimulation was performed as a short-term treatment for urinary incontinence (Lim et al., 2015). It can be performed with ease in patients: they only sit on the magnetic chair without experiencing any pain.

Electrical neuromodulation may ameliorate lower urinary tract dysfunction ranging from $\mathrm{OAB}$, urge incontinence to interstitial cystitis (Abello and Das, 2018). Although surgical intervention is needed for the placement of a low-amplitude electrical stimulator, programmable adjustments in office-based techniques to afford optimized rates based on the severity of symptoms are also required (Marcelissen et al., 2010). Sacral nerve stimulation or percutaneous tibial nerve stimulation could be performed according to the stimulation level (Marcelissen et al., 2010; Sajadi and Goldman, 2010).

In case of SUI after RP, PFE may improve early continence and QoL after PR (Goonewardene et al., 2018). Furthermore, ONB, wherein a bladder is artificially constructed using various parts of the bowel following radical cystectomy for bladder cancer, is the most extreme urologic condition that requires bladder rehabilitation. The patients should be trained to urination with abdominal pressure right after the surgery performed (Steers, 2000). In ONB, various bladders functional abnormalities such as SUI, nocturnal enuresis (NE), and urinary retention might be experienced (Steers, 2000). Injection of debulking agent or artificial urethral sphincter, an alarm clock in frequent awakening for timed voiding, and CIC are the most effective management methods for SUI, NE, and urinary retention, respectively (Steers, 2000).

\section{BLADDER REHABILITATION IN CHILDREN}

In addition to general voiding dysfunction mentioned above, numerous abnormalities should be considered in children, such as $\mathrm{NE}$ and other dysfunctional voiding (Fig. 1).

$\mathrm{NE}$ is most common voiding abnormality in children that is the voluntary or involuntary wetting with urine and has significant psychological effects on both child and the family (Arda et al., 2016). Bedwetting alarm is a representative therapy for the children with NE. The NE patients should put the alarm device with humidity sensor in their underwear. The bedwetting alarm works by detecting urine; hence, it makes the child hold their urination (Robertson et al., 2014). It also shows a synergic effect when used with drug therapy (Robertson et al., 2014). Positive reinforcement using bedwetting chart or diary with reward system for dry night may also motivate the child, and with these methods, up to $70 \%$ of patients with NE showed definite improvement (Marshall et al., 1973). FMS is proposed as a potent treatment in children with NE under the possible mechanism of cortical arousal (But and Varda, 2006).

Dysfunctional voiding is a type of coordination failure of the detrusor (or pelvic floor muscle) and external sphincter without neuroanatomical abnormality that usually causes lower urinary tract symptom, urinary incontinence, vesicoureteral reflux, and kidney function damage (Glassberg et al., 2010). In other words, affected patients habitually contract their urethral sphincter during voiding, hence it is important to correct toilet habit and posture (Clothier and Wright, 2018). The appropriate posture is to sit securely with comfortable hip abduction that does not stimulate the pelvic floor muscles (Glassberg et al., 2010). Trunk core muscle including pelvic floor relaxation could be attained with full stabilization by supported sitting and relaxed abdominal wall. Neutral lumbar spine position and slightly abducted feet also help attain pelvic floor relaxation (Wennergren et al., 1991). Bladder training, biofeedback, and PFE are appropriate management methods of treating patients with dysfunctional voiding. This method is a form of retraining for normally unconscious physiological process by transition to direct tangible signals. This process is transformed to the signal which may be expressed by monitor or speaker, help restore and facilitate habituation of the normal urination mechanism (Clothier and Wright, 2018).

\section{PENILE REHABILITATION}

Given the increasing incidence of prostate cancer, ED after RP is also increased (Köhler et al., 2014). RP is the leading cause of ED after a medical procedure and may cause long-term psychological and functional dysfunction (Köhler et al., 2014). Other urologic and radical surgeries, such as prostatectomy, also increase the incidence of ED (Chung and Woo, 2016; De Luca et al., 1996).

In penile rehabilitation, early and recurrent initiations of erections might accelerate local blood circulation to the penis in order to prevent corporal hypoxia and subsequent cavernosal fibrosis and to facilitate vascular and neural recovery (Carrier et al., 1995; Cui et al., 2017; Iacono et al., 2008; Mulhall et al., 2010). Furthermore, current rehabilitation uses traditional methods to treat ED, such as phosphodiesterase type 5 inhibitor (PDE5i) medication (Brock et al., 2003), intracavernosal (IC) injection therapy (Montorsi et al., 1997), intraurethral alprostdil (Hatzimouratidis et al., 2016), and vacuum erection device (Raina et al., 2006) (Fig. 2). In addition, PFE was also reported to improve ED after RP (Goone- 


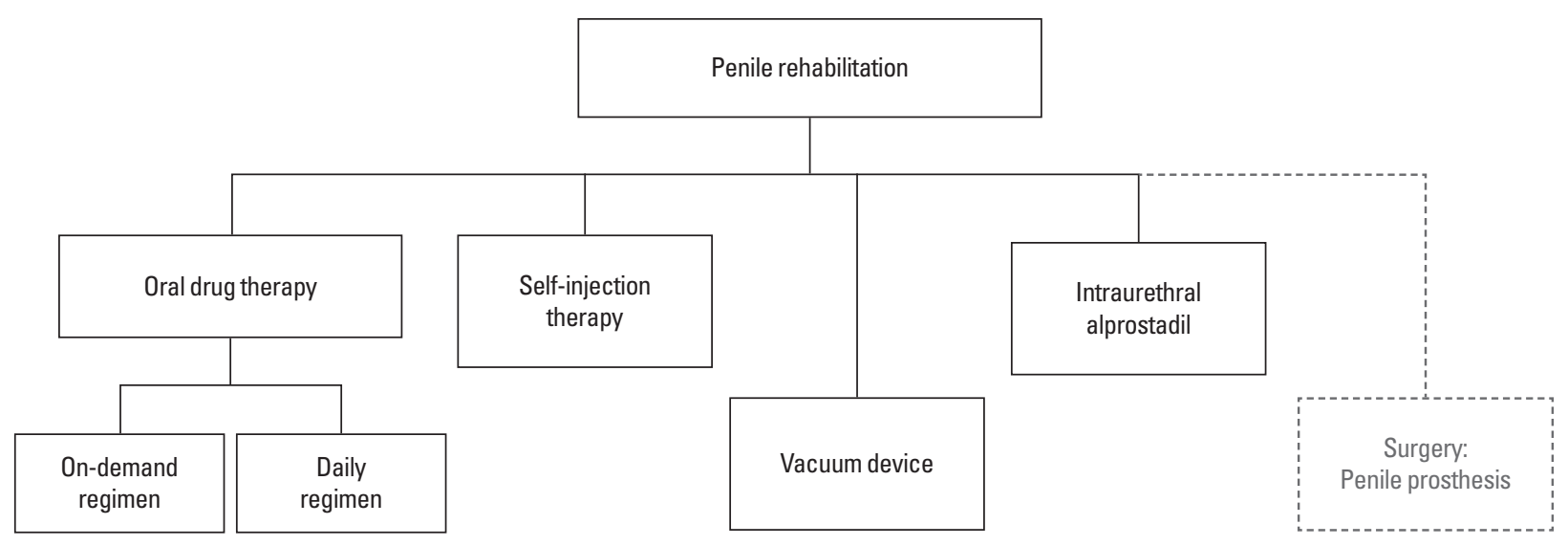

Fig. 2. Penile rehabilitation modality.

wardene et al., 2018).

Oral PDE5i medication therapy is a very convenient method, and diverse medications with similar mechanism of action were developed. While most rehabilitation modalities are used by on-demand basis only, PDE5i has unique characteristics: it can be used for both on-demand and persistent usage (Montorsi et al., 2008). Self-injection to one's own penis (IC injection) is a quite effective but difficult method to employ because it is hard to learn and troublesome to perform (Belew et al., 2015). Complications such as pain, hematoma, priapism, and penile fibrosis are one of the problems with IC therapy (Belew et al., 2015). Intraurethral alprostadil is a noninvasive self-applying method before intercourse, which is known that is easy to learn and safe but has relatively low efficacy (Hatzimouratidis et al., 2016) (Fig. 2). Unlike IC injection therapy, which has that risk, vacuum device is very safe and easy method to apply (Iacono et al., 2008). The device generates negative pressure and induces congestion in the penis to cause erection. Its disadvantage is the operability of the device, and it colds the penis, but it attains a good erection function (Engel, 2011).

Although some controversy exists on whether penile rehabilitation can improve the recovery of spontaneous erection, these methods are confirmed to enhance erectile function during treatment (Liu et al., 2017). Therefore, many urologists continue to recommend and prescribe some of these penile rehabilitation methods after surgery.

\section{CONFLICT OF INTEREST}

No potential conflict of interest relevant to this article was reported.

\section{REFERENCES}

Abello A, Das AK. Electrical neuromodulation in the management of lower urinary tract dysfunction: evidence, experience and future prospects. Ther Adv Urol 2018;10:165-173.

Arda E, Cakiroglu B, Thomas DT. Primary nocturnal enuresis: a review. Nephrourol Mon 2016;8:e35809.

Belew D, Klaassen Z, Lewis RW. Intracavernosal Injection for the diagnosis, evaluation, and treatment of erectile dysfunction: a review. Sex Med Rev 2015;3:11-23.

Briganti A, Montorsi F. Penile rehabilitation after radical prostatectomy. Nat Clin Pract Urol 2006;3:400-401.

Brock G, Nehra A, Lipshultz LI, Karlin GS, Gleave M, Seger M, PadmaNathan H. Safety and efficacy of vardenafil for the treatment of men with erectile dysfunction after radical retropubic prostatectomy. J Urol 2003;170(4 Pt 1):1278-1283.

But I. Conservative treatment of female urinary incontinence with functional magnetic stimulation. Urology 2003;61:558-561.

But I, Varda NM. Functional magnetic stimulation: a new method for the treatment of girls with primary nocturnal enuresis? J Pediatr Urol 2006; 2:415-418.

Carrier S, Hricak H, Lee SS, Baba K, Morgan DM, Nunes L, Ross GY, Phillips TL, Lue TF. Radiation-induced decrease in nitric oxide synthase-containing nerves in the rat penis. Radiology 1995;195:95-99.

Choi H, Bae JH. Overview of the epidemiology of lower urinary tract dysfunction in South Korea. Int Neurourol J 2016;20:91-100.

Chung A, Woo HH. Preservation of sexual function when relieving benign prostatic obstruction surgically: can a trade-off be considered? Curr Opin Urol 2016;26:42-48.

Clothier JC, Wright AJ. Dysfunctional voiding: the importance of non-invasive urodynamics in diagnosis and treatment. Pediatr Nephrol 2018; 
33:381-394.

Costantini E, Illiano E, Giannitsas K, Prestipino M, Pastore AL, Carbone A, Palleschi G, Balsamo R, Natale F, Villari D, Bini V, Maruccia S, Filocamo MT, Zucchi A. Urological dysfunction in young women: an inheritance of childhood? BJU Int 2018;121:453-457.

Cui K, Luan Y, Wang T, Zhuan L, Rao K, Wang SG, Ye ZQ, Liu JH, Wang DW. Reduced corporal fibrosis to protect erectile function by inhibiting the Rho-kinase/LIM-kinase/cofilin pathway in the aged transgenic rat harboring human tissue kallikrein 1. Asian J Androl 2017;19:67-72.

De Luca V, Pescatori ES, Taher B, Zambolin T, Giambroni L, Frego E, Cosciani Cunico S. Damage to the erectile function following radical pelvic surgery: prevalence of veno-occlusive dysfunction. Eur Urol 1996; 29:36-40.

Dumoulin C, Hay-Smith EJ, Mac Habée-Séguin G. Pelvic floor muscle training versus no treatment, or inactive control treatments, for urinary incontinence in women. Cochrane Database Syst Rev 2014;(5): CD005654.

Engel JD. Effect on sexual function of a vacuum erection device post-prostatectomy. Can J Urol 2011;18:5721-5725.

Eton DT, Lepore SJ. Prostate cancer and health-related quality of life: a review of the literature. Psychooncology 2002;11:307-326.

Glassberg KI, Combs AJ, Horowitz M. Nonneurogenic voiding disorders in children and adolescents: clinical and videourodynamic findings in 4 specific conditions. J Urol 2010;184:2123-2127.

Goonewardene SS, Gillatt D, Persad R. A systematic review of PFE preprostatectomy. J Robot Surg 2018 Mar 21 [Epub]. https://doi.org/10. 1007/s11701-018-0803-8.

Hatzimouratidis K, Salonia A, Adaikan G, Buvat J, Carrier S, El-Meliegy A, McCullough A, Torres LO, Khera M. Pharmacotherapy for erectile dysfunction: recommendations from the Fourth International Consultation for Sexual Medicine (ICSM 2015). J Sex Med 2016;13:465-488.

Iacono F, Prezioso D, Somma P, Chierchia S, Galasso R, Micheli P. Histopathologically proven prevention of post-prostatectomy cavernosal fibrosis with sildenafil. Urol Int 2008;80:249-252.

Köhler N, Friedrich M, Gansera L, Holze S, Thiel R, Roth S, Rebmann U, Stolzenburg JU, Truss MC, Fahlenkamp D, Scholz HJ, Brähler E. Psychological distress and adjustment to disease in patients before and after radical prostatectomy. Results of a prospective multi-centre study. Eur J Cancer Care (Engl) 2014;23:795-802.

Lim R, Lee SW, Tan PY, Liong ML, Yuen KH. Efficacy of electromagnetic therapy for urinary incontinence: a systematic review. Neurourol Urodyn 2015;34:713-722.

Liu C, Lopez DS, Chen M, Wang R. Penile rehabilitation therapy follow- ing radical prostatectomy: a meta-analysis. J Sex Med 2017;14:14961503.

Marcelissen TA, Leong RK, de Bie RA, van Kerrebroeck PE, de Wachter SG. Long-term results of sacral neuromodulation with the tined lead procedure. J Urol 2010;184:1997-2000.

Marshall S, Marshall HH, Lyon RP. Enuresis: an analysis of various therapeutic approaches. Pediatrics 1973;52:813-817.

Montorsi F, Brock G, Lee J, Shapiro J, Van Poppel H, Graefen M, Stief C. Effect of nightly versus on-demand vardenafil on recovery of erectile function in men following bilateral nerve-sparing radical prostatectomy. Eur Urol 2008;54:924-931.

Montorsi F, Guazzoni G, Strambi LF, Da Pozzo LF, Nava L, Barbieri L, Rigatti P, Pizzini G, Miani A. Recovery of spontaneous erectile function after nerve-sparing radical retropubic prostatectomy with and without early intracavernous injections of alprostadil: results of a prospective, randomized trial. J Urol 1997;158:1408-1410.

Mulhall JP, Bella AJ, Briganti A, McCullough A, Brock G. Erectile function rehabilitation in the radical prostatectomy patient. J Sex Med 2010;7(4 Pt 2):1687-1698.

Newman DK. Pelvic floor muscle rehabilitation using biofeedback. Urol Nurs 2014;34:193-202.

Olujide LO, O'Sullivan SM. Female voiding dysfunction. Best Pract Res Clin Obstet Gynaecol 2005;19:807-828.

Raina R, Agarwal A, Ausmundson S, Lakin M, Nandipati KC, Montague DK, Mansour D, Zippe CD. Early use of vacuum constriction device following radical prostatectomy facilitates early sexual activity and potentially earlier return of erectile function. Int J Impot Res 2006;18: 77-81.

Robertson B, Yap K, Schuster S. Effectiveness of an alarm intervention with overlearning for primary nocturnal enuresis. J Pediatr Urol 2014;10: 241-245.

Sajadi KP, Goldman HB. Percutaneous tibial nerve stimulation and overactive bladder. Curr Urol Rep 2010;11:293-295.

Steers WD. Voiding dysfunction in the orthotopic neobladder. World J Urol 2000;18:330-337.

Walsh PC, Schlegel PN. Radical pelvic surgery with preservation of sexual function. Ann Surg 1988;208:391-400.

Wein AJ. Bladder training for urinary incontinence in adults. J Urol 2005; 173:1263-1264

Wennergren HM, Oberg BE, Sandstedt P. The importance of leg support for relaxation of the pelvic floor muscles. A surface electromyograph study in healthy girls. Scand J Urol Nephrol 1991;25:205-213. 